\title{
Levantamento da produção de morangos no Oeste Catarinense
}

\author{
Thiago Marchi', Dirceu Júnior Ferri², Caroline Möller Scholz ${ }^{3}$ e Jeferson João Soccol ${ }^{4}$
}

Resumo - O objetivo do trabalho foi realizar um levantamento de dados sobre a produção de morangos no Oeste Catarinense, que possibilite o planejamento de ações de assistência técnica no cultivo e de desenvolvimento da cadeia produtiva. 0 levantamento foi realizado no ano de 2019, através da aplicação de um questionário aos extensionistas da Epagri. Os dados pesquisados foram: número de produtores por munícipio, sistema de cultivo, número de plantas por produtor e cultivares plantados. Os resultados demonstram que existem 74 produtores de morango distribuídos em $81 \%$ dos municípios da região. O principal sistema de produção adotado é o semi-hidropônico em bancadas elevadas que se encontra presente em $66 \%$ das propriedades. Dos 74 produtores, $84 \%$ produzem no sistema convencional. Em relação ao número de plantas cultivadas, 50\% possuem menos de 2.500 plantas e $74 \%$ menos de 5.000 plantas. Os cultivares predominantes são San Andreas e Albion.

Termos para indexação: Planejamento estratégico da cadeia produtiva; diagnóstico inicial; diversificação da agricultura familiar; extensão rural.

\section{Strawberry production survey in western Santa Catarina}

\begin{abstract}
The objective of the work was to carry out a survey of data on the production of strawberries in the western region of Santa Catarina, which enables the planning of technical assistance actions in the cultivation and development of the production chain. The survey was carried out in 2019, through the application of a questionnaire to Epagri extension workers. The researched data were the number of growers per municipality, cultivation system, number of plants per grower and the cultivars planted. The results show that there are 74 strawberry growers distributed in $81 \%$ of the municipalities in the region. The main production system adopted is the semi-hydroponic in elevated benches, which is present in $66 \%$ of the properties. Considering the production system of the 74 growers, $84 \%$ are conventional. Regarding the number of cultivated plants, $50 \%$ have less than 2500 plants and $74 \%$ less than 5000 plants. The predominant cultivars are San Andreas and Albion.
\end{abstract}

Index terms: Strategic planning of the production chain; initial diagnosis; diversification of family farming; rural extension.

O Oeste Catarinense é reconhecido por sua expressividade nas cadeias produtivas de suínos, aves e leite. Entretanto, atividades alternativas às tradicionais estão sendo adotadas pelos agricultores familiares da mesorregião que buscam a diversificação e o aumento da renda das propriedades. Dentre estas, destaca-se a horticultura, em especial o cultivo de morango.

Cabe ressaltar que a expansão de atividades alternativas para a diversificação da agricultura familiar exige um planejamento estratégico por parte dos órgãos de apoio e das organizações locais. Neste contexto, Henz (2010) ressal- ta o sucesso da cultura do morangueiro no Espirito Santo, com destaque para ações de órgãos governamentais ligados à agricultura no estado que realizaram trabalhos para superar dificuldades no cultivo desta cultura. Segundo RojasMolina (2016), é necessário o conhecimento da realidade local da produção de morangos para que a assistência técnica possa identificar os gargalos específicos e propor ou divulgar os sistemas de produção mais adequados. Um diagnóstico inicial é um importante norteador de ações neste processo.

Neste sentido, o objetivo do trabalho foi realizar um levantamento da produção de morangos no Oeste Catarinense que possibilite o planejamento de ações de assistência técnica para o cultivo e o desenvolvimento da cadeia produtiva.

O levantamento foi realizado entre agosto e setembro de 2019, através de um questionário aplicado aos extensionistas da Epagri responsáveis pelos municípios pertencentes à Unidade de Gestão Técnica 1 (UGT 1 - Oeste Catarinense). Esta divisão engloba os municípios das Regionais da Epagri de Chapecó (Águas Frias, Campo Erê, Caxambu do Sul, Chapecó, Cordilheira Alta, Coronel Freitas, Formosa do Sul, Guatambu, -

Recebido em 6/2/2020. Aceito para publicação em 21/7/2020.

${ }^{1}$ Engenheiro-agrônomo, Epagri/Escritório Municipal de Lajeado Grande, Rua Vitória, 503, Centro, Lajeado Grande, SC, 89.828-000, e-mail: thiagomarchi@ epagri.sc.gov.br.

${ }^{2}$ Engenheiro-agrônomo, Epagri/Escritório Municipal de Guatambu, Rua João Bortolo Favara, SN, Centro, Guatambu, SC, 89.817-000, e-mail: dirceuferri@ epagri.sc.gov.br.

${ }^{3}$ Engenheiro-agrônomo, Epagri/Escritório Municipal de Chapecó, Av. Nereu Ramos, 1750 E, Bairro Passo dos Fortes - Mercado Público Regional, Chapecó, SC, 89.805-100, e-mail: carolinemoller@epagri.sc.gov.br.

${ }^{4}$ Engenheiro-agrônomo, Epagri/Escritório Municipal de Xaxim, Rua 10 de Novembro, 898, Centro, Xaxim, SC, 89.825-000, e-mail: jefersonsoccol@epagri. sc.gov.br. 
Irati, Jardinópolis, Nova Erechim, Nova Itaberaba, Novo Horizonte, Planalto Alegre, Quilombo, Santiago do Sul, São Bernardino, São Lourenço do Oeste e União do Oeste) e de Xanxerê (Abelardo Luz, Bom Jesus, Coronel Martins, Entre Rios, Faxinal dos Guedes, Galvão, Ipuaçu, Jupiá, Lajeado Grande, Marema, Ouro Verde, Passos Maia, Ponte Serrada, São Domingos, Vargeão, Xanxerê e Xaxim).

Em cada município, para o ano de 2019, foram registrados o número de produtores e os seguintes dados dos cultivos: sistema de produção adotado (convencional, orgânico ou em transição); sistema de cultivo (em solo ou bancada; cultivados em substrato ou solo; tipo de abrigo utilizado); número de plantas e cultivares utilizados. Os dados foram sistematizados a fim de definir os parâmetros: número de produtores comerciais de morango por município, número de plantas de morango por município, porcentagem de produtores em cada sistema de produção, número de produtores por sistema de cultivo, número de produtores por cultivar e número de plantas por produtor.

Na Tabela 1 observa-se o número de produtores comerciais e o número de plantas de morango por município. Em 29 dos 36 municípios existem produtores de morango, o que representa $81 \%$ dos municípios da região. Chapecó, a cidade mais populosa da região, destacase com o maior número de produtores (quatorze) e a maior quantidade de plantas cultivadas (176.500), enquanto os municípios de Águas Frias, Irati, Jardinópolis, Nova Itaberaba, Santiago do Sul, São Lourenço do Oeste e União do Oeste não possuem produtores comerciais de morango.

O número total de produtores de morango no Oeste Catarinense em 2019 foi de 74 estabelecimentos. RojasMolina (2016) cita que em 2015 a região possuía apenas 7 produtores comerciais de morango. Acredita-se que este aumento esteja relacionado à elevada produtividade e à rentabilidade econômica desta cultura, ao amplo conhecimento e
Tabela 1. Número de produtores comerciais de morango e número de plantas de morango por município do Oeste Catarinense no ano de 2019

Table 1. Number of commercial strawberry growers and number of strawberry plants by municipality of western Santa Catarina region in 2019

\begin{tabular}{|c|c|c|}
\hline Município & Produtores & Número de plantas \\
\hline Chapecó & 14 & 176.500 \\
\hline Guatambu & 4 & 69.500 \\
\hline Xanxerê & 6 & 69.500 \\
\hline Faxinal dos Guedes & 4 & 30.000 \\
\hline Nova Erechim & 2 & 25.000 \\
\hline Abelardo Luz & 5 & 24.000 \\
\hline Campo Erê & 2 & 11.000 \\
\hline Ipuaçu & 2 & 9.500 \\
\hline Coronel Freitas & 3 & 9.500 \\
\hline Vargeão & 1 & 9.100 \\
\hline Ponte Serrada & 3 & 8.200 \\
\hline Novo Horizonte & 2 & 7.000 \\
\hline São Domingos & 2 & 6.900 \\
\hline Ouro Verde & 2 & 6.700 \\
\hline Xaxim & 3 & 6.000 \\
\hline Quilombo & 4 & 5.200 \\
\hline Coronel Martins & 1 & 5.000 \\
\hline Caxambu do Sul & 1 & 4.500 \\
\hline Entre Rios & 1 & 4.000 \\
\hline Marema & 1 & 3.500 \\
\hline Formosa do Sul & 1 & 2.000 \\
\hline Planalto Alegre & 1 & 2.000 \\
\hline Cordilheira Alta & 1 & 1.700 \\
\hline São Bernardino & 2 & 1.700 \\
\hline Jupiá & 1 & 1.500 \\
\hline Passos Maia & 1 & 1.200 \\
\hline Lajeado Grande & 2 & 1.160 \\
\hline Bom Jesus & 1 & 1.000 \\
\hline Galvão & 1 & 1.000 \\
\hline Águas Frias & 0 & 0 \\
\hline Irati & 0 & 0 \\
\hline Jardinópolis & 0 & 0 \\
\hline Nova Itaberaba & 0 & 0 \\
\hline Santiago do Sul & 0 & 0 \\
\hline São Lourenço do Oeste & 0 & 0 \\
\hline União do Oeste & 0 & 0 \\
\hline TOTAL & 74 & 503.860 \\
\hline
\end{tabular}


aceitação pelo consumidor e pela difusão das tecnologias de cultivo na região (ANTUNES \& PERES, 2013; FAGUERAZZI et al., 2017b).

O sistema de produção predominante no Oeste Catarinense é o convencional, com $84 \%$ dos produtores da mesorregião produzindo neste sistema (Figura 1). Os produtores orgânicos representam $16 \%$ do número total de produtores, sendo que destes, $4 \%$ estão em transição (não estão certificados) e 12\% possuem certificação.

Apesar do crescente interesse pelos produtores brasileiros em cultivar morangos fora do solo, ainda a produção no solo, com uso de sistema de irrigação e fertirrigação por gotejamento, revestimento dos canteiros por mulching e cobertura dos plantios em túneis baixos é a técnica predominante no Brasil (ANTUNES \& PERES, 2013). Entretanto, no Oeste Catarinense, observa-se que o cultivo em canteiros no solo é adotado por apenas 25 produtores, o que representa $34 \%$ dos produtores de morango da mesorregião (Figura 2). Já o cultivo em bancada com uso de sacos de cultivo, denominados "slabs" e sistema semi-hidropônico é adotado por 49 produtores, ou seja, $66 \%$ dos produtores. Segundo Faguerazzi et al. (2017b), apesar deste sistema exigir um alto investimento inicial para instalação, possui a vantagem de obter maior rendimento da mão de obra e melhora a ergonomia para o trabalhador. Há ainda na região

\section{Em transição para}

o sistema orgânico

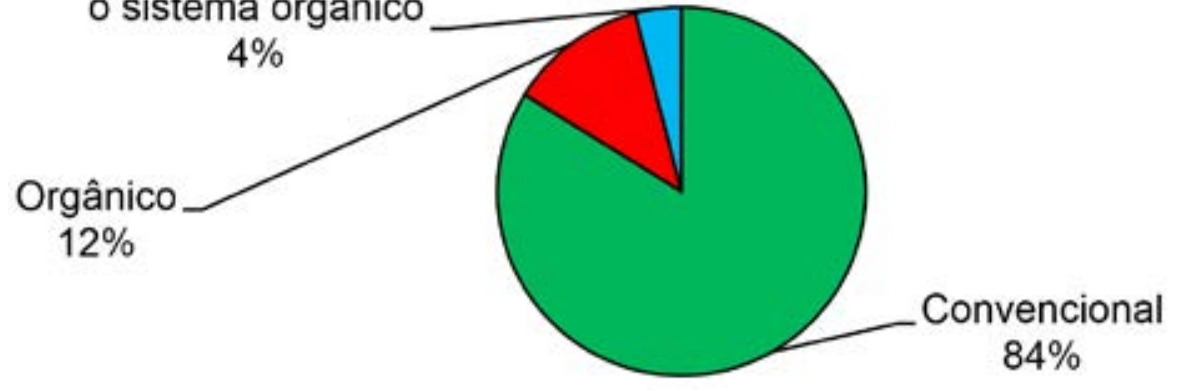

Figura 1. Sistema de produção utilizado por produtores de morango do Oeste Catarinense em 2019

Figure 1. Production system used by strawberry producers in western Santa Catarina in 2019

cinco agricultores que utilizam sistemas de cultivo elevados em vasos ou calhas, principalmente produtores orgânicos, que estão tentando adaptar o sistema de cultivo para facilitar o trabalho.

Os cultivares mais utilizados na região em 2019 foram o San Andreas, por 53 produtores, e o Albion, por 50 agricultores (Figura 3). Estes dois cultivares, juntamente com o cv. Camarosa, representam $60 \%$ do cultivo nacional de morango, destacando-se Albion como o cultivar mais cultivado e San Andreas como o cultivar com maior crescimento de mercado (FAGHERAZZI et al., 2017b). Já em Santa Catarina $84,4 \%$ dos cultivos são realizados com os cultivares Albion, Aromas e Camarosa (ROJAS-MOLINA, 2016). O cultivar Pircinque, introduzido recentemente no Brasil, destacase também por estar presente em 11 cultivos na mesorregião. Este cultivar é considerado promissor devido a sua produtividade e pelas características de qualidade do fruto (FAGHERAZZI et al., 2017a). Na mesorregião também foi observado em menor expressão o uso dos cultivares Camarosa, Aromas, Camino Real, Portola, Monterey, Fronteras e Merced. Apenas três agricultores não souberam informar o cultivar de morango utilizado.

O número de plantas de morangueiro cultivadas por agricultor pode ser observado na Figura 4. O Oeste Catarinense possui 37 produtores de morango com até 2.500 plantas e 18 produtores com 2.501 a 5.000 plantas, ou seja, $74 \%$ do número de produtores da mesorregião estão nestas duas classes. 0 baixo número de plantas por produtor mostra que os cultivos de morangos representam ainda uma renda secundária para as propriedades.

A produção de morangos no Oeste Catarinense caracteriza-se por empre-॰

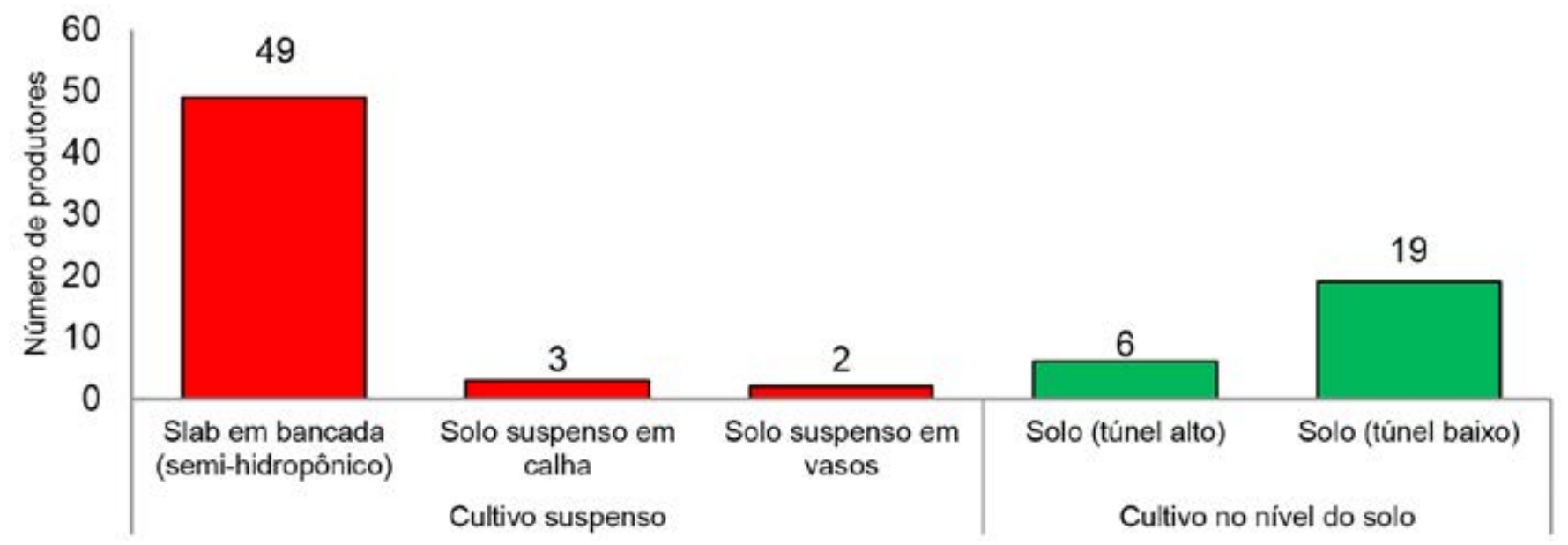

Figura 2. Número de produtores de morango por sistema de cultivo em 2019 no Oeste Catarinense

Figure 2. Number of strawberry growers by cropping system in 2019 in western Santa Catarina 


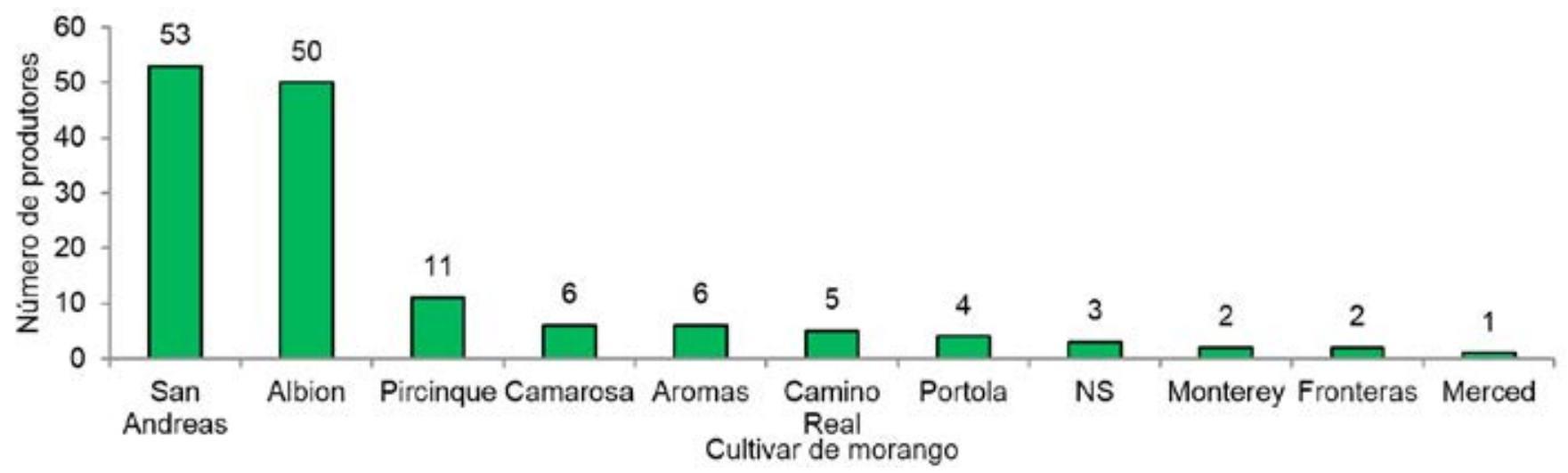

Figura 3. Número de produtores de morango por cultivar utilizado em 2019 no Oeste Catarinense (NS: não souberam informar)

Figure 3. Number of strawberry growers per cultivar used in 2019 in western Santa Catarina (NS: could not inform)

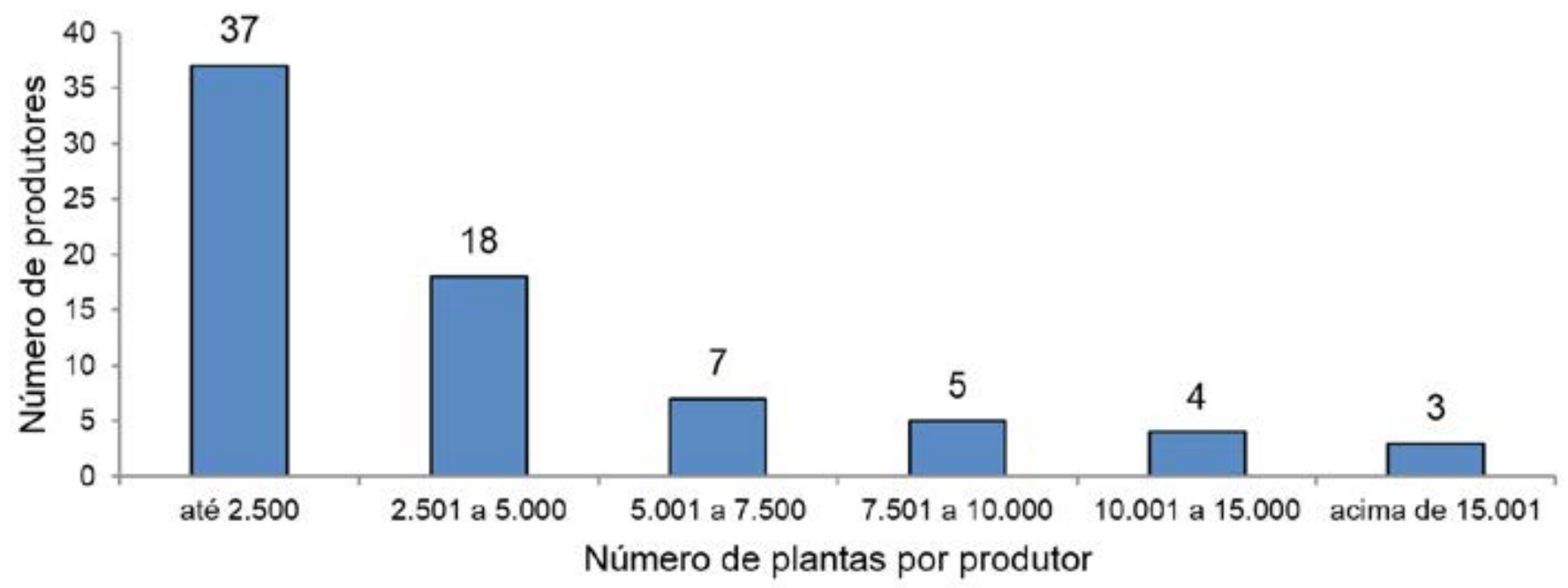

Figura 4. Número de produtores de morango no Oeste Catarinense de acordo com o número de plantas por produtor em 2019

Figure 4. Number of strawberry growers in Western Santa Catarina according to the number of plants per grower in 2019

endimentos novos, com pequeno número de plantas por produtor, utilizando sistema de produção convencional com cultivo suspenso em sistema semihidropônico, principalmente com plantio dos cultivares San Andreas e Albion.

\section{Agradecimentos}

Os autores agradecem os extensionistas da Epagri da UGT 1 pelo apoio na coleta de informações que possibilitaram a elaboração desta publicação.

\section{Referências}

ANTUNES, L.E.C.; PERES, N.A. Strawberry Production in Brazil and South America. In- ternational Journal of Fruit Science, v.13, n.1-2, p.156-161. 2013. DOI: https://doi.org /10.1080/15538362.2012.698147

FAGHERAZZI, A.F., BORTOLINI, A.J., ZANIN, D.S., BISOL, L., DOS SANTOS, A.M., GRIMALDI, F., KRETZSCHMAR, A.A., BARUZZI, G., FAEDI, W., LUCCHI, P., RUFATO, L. New strawberry cultivars and breeding activities in Brazil. Acta Horticulturae, Haia, v.1156, n.1, 167-170. 2017a. DOI: https:// doi.org/10.17660/ActaHortic.2017.1156.24

FAGHERAZZI, A.F., GRIMALDI, F., KRETZSCHMAR, A.A., MOLINA, A.R., GONÇALVES, M.A., ANTUNES, L.E.C., BARUZZI, G., RUFATO, L. Strawberry production progress in Brazil. Acta Horticulturae, Haia, v.1156, n.1, 937-940, 2017b. DOI: https://doi. org/10.17660 / ActaHortic.2017.1156.138

HENZ, G.P. Desafios enfrentados por agricultores familiares na produção de morango no Distrito Federal. Horticultura Brasileira, v. 28, n. 3, p. 260-265, 2010. DOI: https://doi. org/10.1590/S0102-05362010000300003.

ROJAS-MOLINA, A.R. A cultura do morangueiro (fragaria $\mathrm{x}$ ananassa duch.) no estado de Santa Catarina: sistemas de produção e riscos climáticos. 195p. Dissertação (Mestrado em Recursos Genéticos Vegetais), Universidade Federal de Santa Catarina, Florianópolis, 2016. Disponível em: https://repositorio.ufsc.br/xmlui/bitstream/handle/123456789/169228/342144. pdf?sequence $=1 \&$ isAllowed $=y$. Acesso em: 05 de março de 2020 . 